\title{
Tip 2 Diyabetli Bireylerde Abdominal Obezite/Adipozite ve Aterojenik Belirteçlerin Değerlendirilmesi
}

\author{
Evaluation of Abdominal Obesity/Adiposity and Atherogenic Predictors in Individuals with Type \\ 2 Diabetes
}

\author{
Özge Küçükerdönmez ${ }^{1}$, Merve Şeyda Karaçil Ermumcu ${ }^{2}$, Selda Seçkiner ${ }^{3}$, Eda Köksal ${ }^{4}$
}

Geliş tarihi/Received: 05.02.2018 • Kabul tarihi/Accepted: 11.04.2018

\section{ÖZET}

Amaç: Bu çalışmada tip 2 diabetes mellituslu (DM) bireylerde insülin direnciyle ilişkili olan abdominal obezite/adipozite göstergeleri ile aterojenik indeksin değerlendirilmesi amaçlanmıştır.

Bireyler ve Yöntem: Bu kesitsel çalışmaya yaşları 18-65 yıl arasında değişen tip 2 DM’li yetişkin 100 gönüllü birey dahil edilmiştir. Bireylere ait genel ve sağlık bilgileri anket formu aracılığıyla alınmıştır. Bireylerin antropometrik ve vücut bileşim ölçümleri araştırmacılar tarafından kurallarına uygun şekilde yapılmıştır. Biyokimyasal bulgularından açlık glukoz, açlık insülin, glukozillenmiş hemoglobin (HbA1c), kan lipit parametreleri alınmıştır. Abdominal obezitenin değerlendirilmesinde bel kalça oranı ve bel boy oranı, abdominal adipozitenin değerlendirilmesinde viseral adipozite indeksi (VAİ) ile koniklik indeksi (Kİ) hesaplanmıştır. Ayrıca vücut adipozite indeksi (BAÍ) hesaplanmıştır. Ateroskleroz risk değerlendirilmesinde serum aterojenik indeksi (Aİ) kullanılmıştır. Bireylerin insülin direnci değerlendirilmesinde homeostaz model değerlendirmesi (HOMA-IR) hesaplanmıştır.

Bulgular: Çalışmaya dahil edilen erkek (\%91.2) ve kadın (\% 98.5) bireylerin tamamına yakınının şişman olduğu saptanmıştır. Bel boy oranına göre kadınların (\%100) tamamının erkeklerin ise \%94.1’inin hastalık riskinin yüksek olduğu belirlenmiştir. Aterojenik indeks sınıflamasına göre erkeklerin \%85.3’ü, kadınların ise \%83.3’ü yüksek riskli ateroskleroz grubundadır. Bireylerin insülin direnciyle Beden Kütle İndeksi (BKİ) $(r=0.212, p=0.035)$, bel çevresi $(r=0.222, p=0.027)$, VAİ $(r=0.323, p=0.001)$, Aİ $(r=0.318, p=0.001)$, viseral yağlanma \% $(r=0.201, p=0.044)$, HbA1c $(r=0.297, p=0.003)$ ve trigliserit düzeylerinin $(r=0.289$, $\mathrm{p}=0.004$ ) pozitif ilişkili olduğu saptanmıştır. Bireylerin aterojenik indeks ile abdominal obezite/adipozite göstergeleri arasındaki ilişki değerlendirildiğinde ise erkeklerde Aİ, yaş $(r=0.414, p=0.015)$ ve VAİ $(r=0.778, p=0.000)$ ile kadınlarda ise bel kalça oranı ( $r=0.250, p=0.043)$, bel boy oranı $(r=0.264, p=0.032)$, VAİ $(r=0.708, p=0.000)$ ve açlık insülin değeriyle ( $r=0.271$, $\mathrm{p}=0.006)$ pozitif ilişkili bulunmuştur.

Sonuç: Artmış Aİ tip 2 DM riskinde artışla ilişkili olup kardiyovasküler hastalık gelişimini olumsuz etkilemektedir. Buna bağlı olarak Aİ tip 2 DM’li bireylerde kardiyovasküler hastalık risk tahmininde objektif bir gösterge olarak kullanılabilir. Ancak tip 2 DM bireylerde kardiyovasküler hastalıklar açısından en iyi risk tahminini bulmak için daha ileri çalışmalara gereksinme vardır.

Anahtar kelimeler: Tip 2 diabetes mellitus, abdominal obezite, abdominal adipozite, aterojenik indeks

1. İletişim/Correspondence: Ege Üniversitesi, Sağlık Bilimleri Fakültesi, Beslenme ve Diyetetik Bölümü, İzmir, Türkiye • E-posta: dytozgek@hotmail.com (1) https://orcid.org/0000-0003-2228-8917

2. Gazi Üniversitesi, Sağlık Bilimleri Fakültesi, Beslenme ve Diyetetik Bölümü, Ankara, Türkiye

(1) https://orcid.org/0000-0002-2023-8433
3. Ege Üniversitesi, Tıp Fakültesi, İç Hastalıkları Anabilim Dalı, Endokrinoloji ve Metabolizma Hastalıkları Bilim Dalı, İzmir, Türkiye (D) https://orcid.org/0000-0002-5899-4998

4. Gazi Üniversitesi, Sağlık Bilimleri Fakültesi, Beslenme ve Diyetetik Bölümü, Ankara, Türkiye

(D) https://orcid.org/0000-0002-7930-9910 


\section{ABSTRACT}

Aim: This study aimed to evaluate atherogenic index with abdominal obesity/adiposity indicators associated with insulin resistance in individuals with type 2 diabetes mellitus (DM).

Subjects and Methods: This cross-sectional study was conducted on 100 patients with type 2 DM aged 18-65 years. The general and health information of individuals was obtained by a questionnaire. Anthropometric and body composition measurements of individuals were applied by the researchers in accordance with its rules. Biochemical findings (fasting glucose, fasting insulin, glycated haemoglobin (HbA1c), and blood lipid parameters) were taken. Waist hip ratio and waist to height ratio were calculated for evaluating abdominal obesity. Visceral adiposity index (VAI) and conicity index (CI) were calculated for evaluating abdominal adiposity and body adiposity index (BAI) was also calculated. Serum atherogenic index (AI) was used for assessment of atherosclerosis risk. Homeostasis model assessment of insulin resistance (HOMA-IR) was calculated for evaluation of insulin resistance.

Results: Almost all of the men (91.2\%) and women (98.5\%) were obese. Accordingly depending on waist to height ratio, all of women (100\%) and $94.1 \%$ of men had high risk of disease. Overall $85.3 \%$ of men and $83.3 \%$ of women were in high atherosclerosis risk group according to atherogenic index classification. There was a positive correlation between insulin resistance and BMI ( $r: 0.212$; $p$ : 0.035), waist circumference ( $r=0.222 ; p=0.027)$, VAI ( $r=0.323 ; p=0.001)$, AI $(r=0.318 ; p=0.001)$, visceral adiposity ( $r=0.201, p=0.044)$, HbA1c $(r=0.297, p=0.003)$ and triglyceride levels $(r=0.289, p=0.004)$. There was a positive correlation between AI and age $(r=0.414, p=0.015)$, VAI $(r=0.778 ; p=0.000)$ in males and waist to hip ratio $(r=0.250, p=0.043)$, waist to height ratio $(r=0.264, p=0.032)$, VAI $(r=0.708, p=0.000)$ and fasting insulin value $(r=0.271, p=0.006)$ in females.

Conclusion: Increased AI is associated with increased risk of type 2 DM and it adversely affects the development of cardiovascular disease. AI can be used as an objective indicator in predicting cardiovascular disease risk in individuals with type 2 DM. However, further studies are needed to find the best risk prediction for cardiovascular diseases in individuals with type 2 DM.

Keywords: Type 2 diabetes mellitus, abdominal obesity, abdominal adiposity, atherogenic index

\section{GİRIŞ}

Diabetes mellitus (DM), insülin eksikliği ya da insülin etkisindeki bozulmalar nedeniyle organizmanın karbonhidrat, yağ ve proteinlerden yeterince yararlanamadığı kronik bir metabolizma hastalığıdır (1). Dünya genelinde diyabetli birey sayısı artıs eğilimindedir. Uluslararası Diyabet Federasyonu (International Diabetes Federation- IDF) 2017 yll verilerine göre dünyada 425 milyon diyabetli birey bulunmakta ve 352 milyon birey ise tip 2 DM riski altındadır. Ayrıca dünyada diyabet görülme sıklığı \%8.8 olarak belirtilmiştir (2). Ülkemizde hastalığın görülme sıklığı ise 2010 yılında yapılmış olan 'Türkiye Diyabet, Hipertansiyon, Obezite ve Endokrinolojik Hastalıklar Prevalans Çalışması-II' (TURDEP II) sonuçlarına göre 20 yaş üstü yetişkinlerde \%13.7 olarak saptanmıştır (3). Türkiye Kronik Hastalıklar ve Risk Faktörleri Sıklığı Çalışması-2013 verilerine göre ise diyabet sıklığı 15 ve üzeri yaş grubunda \%11, 20 yaş ve üzeri grupta $\% 12.3$ ve $35-79$ yaş grubunda \%17.5 olarak bulunmuştur (4).

Tip 2 DM insülin direnci ve insülin salgısında ciddi azalma durumuyla karakterizedir. İnsülin direnci, hepatik ve periferal hücrelerdeki azalmış insülin duyarlılığı ile tip 2 DM oluşumuna öncülük etmekte olup, ayrıca obezite, glukoz intoleransı, dislipidemi, hipertansiyon ve metabolik hastalık tablosu gibi birçok kronik hastalığın ve sağlık sorununun patofizyolojisinde rol oynamaktadır $(5,6)$. Bunun yaninda obezite, abdominal obezite ve beraberinde getirdiği insülin direnciyle karakterizedir ve tip 2 DM gelişiminde önemli risk etmenidir (7). Bu nedenle diyabetli bireylerde diyabetin belirleyicileri olarak obezite, abdominal obezite ve adipozitenin de 
değerlendirilmesi önem kazanmaktadır $(8,9)$.

Obezite ve insülin direnci tip 2 DM'li bireylerde, hipertrigliseridemi, azalmış serum yüksek dansiteli lipoprotein kolesterol (HDL-K), artmış serum düşük dansiteli lipoprotein kolesterol (LDL-K) düzeyleri ile karakterize diyabetik dislipidemiye ve kardiyovasküler hastalı riskine katkıda bulunan etmenlerdir. Son ylllarda yeni geliştirilen bir parametre olan aterojenik indeks plazma aterojenitesinin bir belirteci olarak tip 2 DM'lilerde kullanılmaya başlanmıştır ve birçok çalışmada tip 2 DM ile ilişkili olduğu belirtilmiştir (10-12).

Son ylllarda insülin direnci, obezite/DM, abdominal obezite/viseral obezite, dislipidemi ve sedanter yaşam tarzı ile sağlıksız beslenme gibi etmenlerin birlikteliği hastalık yükünü dünya çapında arttırmıştır. Gelişmiş ülkelerde ise ölümlerin ana nedenleriyle ilişkilendirilmektedir (13). Bu hastalıklara yol açan değişikliklere, erken yaşam evrelerinde müdahale etmek hastalığın önlenmesi açısından önemlidir. Buna bağlı olarak global sağlık epidemisini oluşturan ve günden güne giderek artan tip 2 DM'li bireylerde obezite, abdominal obezite/adipozite ve kardiyovasküler hastalık risk etmenlerinin bir arada değerlendirilmesi önem kazanmaktadır. Bu çalışmada tip 2 DM bireylerde insülin direnciyle ilişkili olan abdominal obezite/adipozite göstergeleri ile aterojenik indeksin değerlendirilmesi amaçlanmıştır.

\section{BİREYLER VE YÖNTEM}

\section{Araştırma Türü ve Örneklem Seçimi}

$\mathrm{Bu}$ kesitsel çalışmaya, Mayıs-Haziran 2015 tarihleri arasında Bornova/İzmir'de Ege Üniversitesi Tip Fakültesi Hastanesi Endokrinoloji ve Metabolizma Hastalıkları Bilim Dalı’na bağlı polikliniğe başvuran yaşları 18-65 yıl arasında değişen tip 2 DM'li yetişkin kadın $(n=66)$ ve erkek $(n=34)$ gönüllü bireyler alınmıştır. Araştırmaya tip 2 DM'ye eşlik eden herhangi başka bir kronik hastalığı olmayan (kalp-damar hastalıkları, polikistik over sendromu, tiroid işlev bozuklukları, astım vb), hormon tedavisi almayan, lipit düşürücü ajan kullanmayan bireyler dahil edilmiştir.

Çalışmanın etik kurul raporu 15-3.2/6 karar numarası ile Ege Üniversitesi Tıp Fakültesi Klinik Araştırmalar Etik Kurulu'ndan alınmıştır. Bireylerin çalışmaya dahil edilmeden önce yazılı ve sözlü onamları sağlanmıştır.

\section{Veri Toplama Araçları}

Çalışmanın verileri, çalışmaya dahil olmayı kabul eden gönüllülerle yüz yüze görüşülerek anket formu yardımıyla toplanmıştır. Anket formu, bireylere ait genel ve sağlık bilgiler, antropometrik ölçümler [vücut ağırlığı (kg), boy uzunluğu $(\mathrm{cm})$, bel çevresi $(\mathrm{cm})$, kalça çevresi $(\mathrm{cm})]$, vücut bileşim ölçümleri (vücut yağ kütlesi (kg), vücut yağ oranı (\%), viseral yağlanma (\%)] ve biyokimyasal bulgulardan [açlık glukoz (mg/ $\mathrm{dL}$ ), açlık insülini (mU/L), HbA1c (\%), total kolesterol (mg/dL), trigliserit (TG) (mg/dL), HDL kolesterol (mg/ $\mathrm{dL})$, LDL kolesterol (mg/dL)] oluşmaktadır.

\section{Antropometrik Ölçümler ve Vücut Bileşimi Analizi ile Abdominal Obezite/Adipozitenin Değerlendirilmesi}

Araştırmaya dahil edilen bireylerin boy uzunluğu $(\mathrm{cm})$, bel çevresi $(\mathrm{cm})$ ve kalça çevresi $(\mathrm{cm})$ ölçümleri araştırmacılar tarafindan yöntemine uygun şekilde alınmış ve vücut ağırlığı (kg), vücut yağ kütlesi (kg), vücut yağ oranı (\%) ölçümleri biyoelektrik impedans cihazı (Tanita TBF 215) ve abdominal yağlanma ise VISCAN cihazı kullanılarak alınmıştır. Bireylerden ölçümden önce en az 4 saatlik açlık durumunda olmaları, çok fazla sıvı tüketmemiş olmaları (su, çay, kahve), idrara sıkışık olmamaları veya tuvalet ihtiyacını gidermiş olmaları, 24 saat öncesine kadar ağır fiziksel aktivite yapmamış olmaları, üzerlerinde tenlerine temas eden herhangi bir metal eşya bulundurmamaları istenmiştir. Vücut ağırlığı [(kg)/ boy uzunluğu $\left(\mathrm{m}^{2}\right)$ ] formülü ile bireylerin Beden Kütle İndeks'leri (BKİ) hesaplanarak Dünya Sağllk Örgütü sınıflamasına göre zayıf, normal ve şişman olarak gruplandırılmıştır (14). Abdominal obezitenin 
değerlendirilmesinde bel/kalça oranı ve bel boy oranı, abdominal adipozitenin değerlendirilmesinde viseral adipozite indeksi (Viseral adiposite index: VAİ) ile koniklik indeksi (Kİ) hesaplanmıştır $(15,16)$. Ayrıca vücut adipozite indeksi (body adiposite index: BAİ) hesaplanmıştır (17).

VAI $\quad$ (Erkekler $)=\quad[$ Bel çevresi $(\mathrm{cm}) /$ $(36.58+(1.88 \times$ BKİ $)] \times($ trigliserit/1.03 $) \times(1.31 /$ HDL-K $)$

VAi $\quad$ (Kadınlar $)=\quad[$ Bel çevresi $(\mathrm{cm}) /$ $(36.58+(1.88 \times \mathrm{BKI})] \times($ trigliserit/0.81) $\times(1.52 / \mathrm{HDL}-\mathrm{K})$

Ki (Erkekler ve Kadınlar)= Bel çevresi $(\mathrm{m}) /[0.109 \times$ $\sqrt{\text { vücut ağırlığı (kg)/boy uzunluğu (m) }}]$

BAİ (Erkekler ve Kadınlar)= [Kalça çevresi $(\mathrm{cm}) /$ boy uzunluğu (m)1.5]-18

\section{Biyokimyasal Bulgular ve Aterojenik İndeksin Hesaplanması}

Katılımcılarınaçlıkglukoz(mg/dL), açlıkinsülin(mU/L), HbA1c (\%), total kolesterol (mg/dL), TG (mg/dL), HDL kolesterol (mg/dL), LDL kolesterol (mg/dL) değerleri hastanenin biyokimya servisinde analiz edilmiştir.
Serum aterojenik indeksi hesaplanmıştır (18). Bireyler aterojenik indekse göre yüksek riskli $(\mathrm{AI}>0.21)$ ve düşük/orta riskli (AÍ 0.21$)$ olarak iki gruba ayrılmıştır (18). Bireylerin insülin direncini değerlendirmek amacıyla homeostaz model değerlendirmesi (HOMAIR) hesaplanmıştır. HOMA-IR skoru $\geq 2.5$ olan hastalar insülin direnci pozitif olarak belirtilmiştir (19).

HOMA-IR: Açlık glukoz $(\mathrm{mg} / \mathrm{dL}) \times$ Açlık insülin (uIU/L)/405

Aterojenik indeks: ${ }_{\log }(\mathrm{TG} / \mathrm{HDL}-\mathrm{K})$

\section{İstatistiksel Değerlendirme}

Çalışmaya katılan yetişkinlerden elde edilen verilerin değerlendirilmesinde SPSS 16.0 paket programı kullanılmıştır. Bireylerin cinsiyete göre yaş, antropometrik ölçümler, vücut bileşimi, biyokimyasal bulgular, aterojenik indeks ve insülin direnci ve diğer nicel verilerin ortalama ve standart sapma değerlerinin verilmesinde parametrik veriler için t-test, parametrik olmayan veriler için Mann Whitney U testi kullanılmıştır. Verilerin normal dağılıma uygunluğu görsel (histogram ve olasılık grafikleri) ve

Tablo 1. Bireylerin cinsiyete özgü aterojenik indeks, insülin direnci ile abdominal obezite/adipozite göstergelerinin dağılımı

\begin{tabular}{|c|c|c|c|c|c|}
\hline & \multirow[b]{2}{*}{ Sinıflamalar } & \multicolumn{2}{|c|}{ Erkek } & \multicolumn{2}{|c|}{ Kadın } \\
\hline & & $\mathbf{n}$ & $\%$ & $\mathbf{n}$ & $\%$ \\
\hline \multicolumn{6}{|l|}{ BKİ sınıflaması } \\
\hline Normal & $18.50-24.99 \mathrm{~kg} / \mathrm{m}^{2}$ & 3 & 8.8 & 1 & 1.5 \\
\hline Şişman & $\geq 25.00 \mathrm{~kg} / \mathrm{m}^{2}$ & 31 & 91.2 & 65 & 98.5 \\
\hline \multicolumn{6}{|l|}{ Bel boy oran sınıflaması } \\
\hline Hastalık riski düşük & $<0.5$ & 2 & 5.9 & - & - \\
\hline Hastalık riski yüksek & $\geq 0.5$ & 32 & 94.1 & 66 & 100.0 \\
\hline \multicolumn{6}{|l|}{ Bel/kalça oranı } \\
\hline Metabolik komplikasyon riski düşük & $\mathrm{E}=<0.90, \mathrm{~K}=<0.85$ & 2 & 5.9 & 10 & 15.2 \\
\hline Metabolik komplikasyon riski yüksek & $\mathrm{E}=\geq 0.90, \mathrm{~K}=\geq 0.85$ & 32 & 94.1 & 56 & 84.8 \\
\hline \multicolumn{6}{|l|}{ HOMA-IR sınıflaması } \\
\hline İnsülin direnci yok & $<2.5$ & 6 & 17.6 & 13 & 19.7 \\
\hline İnsülin direnci var & $\geq 2.5$ & 28 & 82.4 & 53 & 80.3 \\
\hline \multicolumn{6}{|l|}{ AI sınıflaması } \\
\hline Düşük riskli ateroskleroz & $\leq 0.21$ & 5 & 14.7 & 11 & 16.7 \\
\hline Yüksek riskli ateroskleroz & $>0.21$ & 29 & 85.3 & 55 & 83.3 \\
\hline
\end{tabular}


analitik yöntemler (Kolmogorov-Smirnov/ShapiroWilk testleri) kullanılarak, farklı parametreler arası ilişkiler ise Spearman/Pearson korelasyon testleri kullanılarak incelenmiştir. Tüm istatistiksel analizler için anlamlılık düzeyi $\mathrm{p}<0.05$ olarak kabul edilmiştir.

\section{BULGULAR}

Çalışmaya 18-65 yaşları arasında 34 erkek 66 kadın birey olmak üzere toplam 100 kişi dahil edilmiştir. Bireylerin cinsiyete özgü aterojenik indeks, insülin direnciile abdominal obezite/adipozite göstergelerinin değerlendirilmesi Tablo 1'de gösterilmiştir. Çalışmaya dahil edilen erkek (\%91.2) ve kadın (\%98.5) bireylerin neredeyse tamamına yakınının şişman olduğu saptanmıştır.

Bel boy oranına göre kadınların (\%100.0) tamamının erkeklerin ise \%94.1'inin hastalık riskinin yüksek olduğu belirlenmiştir. Bireyler metabolik risk açısından değerlendirildiğinde kadın (\%84.8) ve erkeklerin (\%94.1) yarısından fazlasında risk yüksek bulunmuştur. Kadın (\%80.3) ve erkeklerde (\%82.4) insülin direnci ise benzer bulunmuştur. Aterojenik indeks sinıflamasına göre erkeklerin \%85.3’ü, kadınların ise \%83.3'ü yüksek riskli ateroskleroz grubundadir.

Bireylerin insülin direnciyle aterojenik indeks, abdominal obezite/adipozite göstergelerinin ve biyokimyasal bulgularının korelasyonlarının değerlendirilmesi Tablo 2'de gösterilmiştir. Bireylerin insülin direnciyle BKİ ( $\mathrm{r}=0.212, \mathrm{p}=0.035)$, bel çevresi $(\mathrm{r}=0.222, \mathrm{p}=0.027), \mathrm{VAI}(\mathrm{r}=0.323, \mathrm{p}=0.001), \mathrm{AI}(\mathrm{r}=0.318$, $\mathrm{p}=0.001)$, viseral yağlanma $(\%)(\mathrm{r}=0.201, \mathrm{p}=0.044)$, HbA1c $(r=0.297, \mathrm{p}=0.003)$ ve trigliserit düzeylerinin $(\mathrm{r}=0.289, \mathrm{p}=0.004)$ pozitif ilişkili olduğu saptanmıştır.

Bireylerin aterojenik indeks ile abdominal obezite/adipozite göstergeleri arasındaki ilişki değerlendirildiğinde ise erkeklerde Aİ yaş $(r=0.414$, $\mathrm{p}=0.015)$ ve VAİ $(\mathrm{r}=0.778, \mathrm{p}=0.000)$, kadınlarda ise

Tablo 2. Bireylerin insülin direnci ile aterojenik indeks, abdominal obezite/adipozite göstergeleri ve biyokimyasal bulguları arasındaki ilişkinin değerlendirilmesi

\begin{tabular}{|c|c|c|c|c|c|c|}
\hline \multirow{3}{*}{ Değişkenler } & \multicolumn{6}{|c|}{ HOMA-IR } \\
\hline & \multicolumn{2}{|c|}{ Erkek } & \multicolumn{2}{|c|}{ Kadın } & \multicolumn{2}{|c|}{ Toplam } \\
\hline & $\mathbf{r}$ & $\mathbf{p}$ & $\mathbf{r}$ & $\mathbf{p}$ & $\mathbf{r}$ & $\mathbf{p}$ \\
\hline Yaş (yll) & -0.307 & 0.077 & -0.090 & 0.471 & -0.176 & 0.080 \\
\hline BKI $\left(\mathrm{kg} / \mathrm{m}^{2}\right)$ & 0.152 & 0.392 & $0.380^{* *}$ & 0.002 & $0.212^{*}$ & 0.035 \\
\hline Bel çevresi $(\mathrm{cm})$ & 0.143 & 0.420 & 0.340 & 0.005 & $0.222 *$ & 0.027 \\
\hline Bel kalça oranı & 0.115 & 0.516 & 0.138 & 0.271 & 0.176 & 0.080 \\
\hline Bel boy oranı & 0.145 & 0.412 & $0.273^{*}$ & 0.027 & 0.125 & 0.216 \\
\hline Viseral yağlanma (\%) & 0.060 & 0.734 & $0.243^{*}$ & 0.049 & $0.201 *$ & 0.044 \\
\hline Toplam vücut yağ yüzdesi (\%) & 0.216 & 0.220 & $0.298^{*}$ & 0.015 & 0.038 & 0.710 \\
\hline VAI & $0.380^{*}$ & 0.027 & $0.369^{* *}$ & 0.002 & $0.323^{* *}$ & 0.001 \\
\hline KI & 0.115 & 0.518 & 0.057 & 0.650 & 0.051 & 0.616 \\
\hline BAI & 0.118 & 0.508 & 0.171 & 0.169 & 0.001 & 0.991 \\
\hline $\mathrm{AI}$ & 0.220 & 0.211 & $0.402^{* *}$ & 0.001 & $0.318^{* *}$ & 0.001 \\
\hline Total kolesterol (mg/dL) & 0.024 & 0.895 & 0.070 & 0.579 & 0.032 & 0.751 \\
\hline $\mathrm{TG}(\mathrm{mg} / \mathrm{dL})$ & 0.150 & 0.398 & $0.422^{* *}$ & 0.000 & $0.289^{* *}$ & 0.004 \\
\hline HDL-K (mg/dL) & -0.321 & 0.064 & $-0.373^{* *}$ & 0.002 & 0.000 & 0.100 \\
\hline LDL-K (mg/dL) & 0.082 & 0.646 & 0.015 & 0.903 & 0.037 & 0.711 \\
\hline HbA1c (\%) & 0.265 & 0.130 & $0.287^{*}$ & 0.019 & $0.297^{* *}$ & 0.003 \\
\hline
\end{tabular}

${ }^{*} p<0.05$,

** <0.01, BKİ: Beden Kütle İndeksi, HOMA-IR: Homeostaz model değerlendirmesi, VAI: Viseral adipozite indeksi, KI: Koniklik indeksi, BAI: Vücut adipozite indeksi, AI: Aterojenik İndeks, TG: Trigliserit 
Tablo 3. Bireylerin aterojenik indeks ile abdominal obezite/adipozite göstergeleri ve bazı biyokimyasal bulguları arasındaki ilişkinin değerlendirilmesi

\begin{tabular}{|c|c|c|c|c|c|c|}
\hline \multirow{3}{*}{ Değişkenler } & \multicolumn{6}{|c|}{ AI } \\
\hline & \multicolumn{2}{|c|}{ Erkek } & \multicolumn{2}{|c|}{ Kadın } & \multicolumn{2}{|c|}{ Toplam } \\
\hline & $\mathbf{r}$ & $\mathbf{p}$ & $\mathbf{r}$ & $\mathbf{p}$ & $\mathbf{r}$ & $\mathbf{p}$ \\
\hline Yaş (yll) & $-0.414^{*}$ & 0.015 & 0.168 & 0.178 & -0.036 & 0.722 \\
\hline BKİ $\left(\mathrm{kg} / \mathrm{m}^{2}\right)$ & 0.318 & 0.066 & 0.178 & 0.154 & $0.213^{*}$ & 0.033 \\
\hline Bel çevresi (cm) & 0.292 & 0.094 & 0.214 & 0.084 & $0.241^{*}$ & 0.016 \\
\hline Bel kalça oranı & 0.082 & 0.645 & $0.250^{*}$ & 0.043 & 0.181 & 0.072 \\
\hline Bel boy oranı & 0.255 & 0.145 & $0.264^{*}$ & 0.032 & $0.244^{*}$ & 0.014 \\
\hline Toplam vücut yağ yüzdesi (\%) & 0.323 & 0.062 & 0.157 & 0.208 & 0.159 & 0.114 \\
\hline Viseral yağlanma (\%) & 0.237 & 0.176 & 0.170 & 0.172 & 0.183 & 0.068 \\
\hline VAI & $0.778 * *$ & 0.000 & $0.708 * *$ & 0.000 & $0.709^{* *}$ & 0.000 \\
\hline KI & 0.116 & 0.512 & 0.186 & 0.135 & 0.165 & 0.101 \\
\hline BAI & 0.268 & 0.125 & 0.151 & 0.226 & 0.149 & 0.140 \\
\hline HbA1c (\%) & 0.061 & .0730 & 0.175 & 0.161 & 0.125 & 0.215 \\
\hline Açlık glukoz (mg/dl) & 0.083 & 0.640 & 0.189 & 0.284 & 0.160 & 0.113 \\
\hline Açlık insülin (mU/l) & 0.232 & 0.061 & $0.324^{* *}$ & 0.008 & $0.271^{* *}$ & 0.006 \\
\hline HbA1c (\%) & 0.061 & 0.730 & .175 & 0.161 & 0.125 & 0.215 \\
\hline
\end{tabular}

${ }^{*} p<0.05,{ }^{* *} p<0.01$

BKİ: Beden Kütle İndeksi, VAI: Viseral adipozite indeksi, KI: Koniklik indeksi, BAI: Vücut adipozite indeksi, AI: Aterojenik indeks

bel kalça oranı $(\mathrm{r}=0.250, \mathrm{p}=0.043)$, bel boy oranı $(\mathrm{r}=0.264, \mathrm{p}=0.032)$, VAİ $(\mathrm{r}=0.708, \mathrm{p}=0.000)$ ve açlik insülin değeriyle $(r=0.271, p=0.006)$ pozitif ilişkili bulunmuştur (Tablo 3).

\section{TARTIŞMA}

Obezite çoğunlukla tip 2 DM’a eşlik etmekle birlikte, bireylerde diyabet riskini belirleyen önemli bir etkendir. Her obez bireyde tip 2 DM gelişmeyebilmektedir, ancak diyabetli bireylerin çoğu obezdir (20). Bu çalışmada tip 2 DM’lu bireylerde şişmanlık sıklığı hem kadın hem de erkeklerde çok yüksektir (Erkek= \%91.2, kadın= \%98.5). Obezite ile abdominal obezite tip 2 DM'in primer nedenleri arasında yer almaktadır (21). Bir meta analiz çalışmasında tip 2 DM'lilerin daha yüksek BKİ değerlerine sahip olduğu belirtilmiş olup (12), bu çalışmada da bireylerin yüksek BKİ değerlerine sahip olduğu, neredeyse tamamının şişman oldukları saptanmıştır (Tablo 1). Ayrıca abdominal obeziteyle insülin direnci arasında sıkı bir ilişki olduğu gösterilmiştir (20). Özellikle yapılan çalışmalarda tip 2 DM'li bireylerde insülin direncinde abdominal obezitenin önemi vurgulanmıştır (22-25). Pek çok çalışmada insülin direnci ve viseral yağlanmanın ilişkili olduğu gösterilmiştir (26,27). Bu çalışmada obezitenin değerlendirilmesinde kullanılan BKİ ve abdominal obezitenin göstergesi olarak kabul edilen bel çevresi ile abdominal adipozitenin yorumlanmasında kullanılan vücut viseral yağlanma yüzdesi (\%) ve VAİ değerleriyle HOMA-IR değeri pozitif ilişkili bulunmuştur (Tablo 2). Özellikle şişman bireylerin adipozitlerinde artan Tümor nekrozis faktör-alfa (TNF-alfa), insülin reseptör sayısının ve işlevinin azalması, artmış serbest yağ asitleri obezite ve insülin direnci ilişkisinin nedenleri arasında gösterilmektedir (20).

Viseral obezitesi olan tip 2 DM'li bireylerde lipit ve lipoprotein metabolizması bozuklukları yaygın olarak görülmekte, diyabetik dislipidemiye neden olmakta ve insülin direncinin yanında kardiyovasküler hastalık riskini de arttırmaktadır. Tip 2 DM’lilerde ortaya çıkan dislipideminin oluşumunda insülin direnci rol oynamaktadır (10). Diyabetik dislipidemi artmış plazma TG ve azalmış HDL-K düzeyleri karakterizedir ve son yllarda tip 2 DM'nin önemli bir komplikasyonu 
olarak kabul edilmektedir. Tip 2 DM önlenmesinde "Kısır döngü" hipotezi olarak belirtilen dislipidemiinsülin direnci-hiperinsülinemi döngüsüne yönelik çalışmalar artmıştır (12,28,29). Yüksek TG düzeyi glukoz oksidasyonunun bozulmasına ve hücre içine girmeye çalışan glukoz ile yarışarak insülin direncine katkıda bulunabilir. Hipertrigliseridemi sıklıkla obeziteye eşlik eder ve yağ hücrelerindeki insülin reseptörlerinin sayısını ve aktivitesini azaltır. Artmış HDL-K insülinin salgısını ve duyarlılığını arttırarak beta hücre işlevinde geliştirici bir rol oynayabilmektedir. Diğer yandan insülin direnci artmış TG düzeyi ve serbest yağ asit düzeyleri ve azalmış HDL-K düzeylerine neden olmaktadır. Buna bağlı olarak, diyabetli birey hem şişman hem de kötü glisemik kontrole sahip ise lipit profili olumsuz etkilenmektedir (12). Bu çalışmada hem kadın hem erkeklerde TG düzeyleriyle insülin direncinin bir göstergesi olan HOMA-IR değeri pozitif ilişkili, kadınlarda ise HDL-K düzeyleriyle HOMA-IR değeri negatif ilişkili bulunmuştur (Tablo 2).

Vücut yağının aşırı artışının, hiperinsülinemi, insülin direnci ve dislipidemi gibi çoklu kardiyovasküler risk etmenlerinin prevalansında bir artışa neden olabileceği ve böylece kardiyovasküler hastalıkları indükleyebileceği kanıtlanmıştır (30). Dobiasova ve Frohlich (31) tarafindan molar trigliserit düzeyinin HDL-K oranının logaritmik bir dönüşümüyle hesaplanan "aterojenik plazma indeksi” olarak adlandırılan parametre geliştirilerek diyabetik dislipidemi ve tip 2 DM riskini değerlendirmede kullanılabileceği belirtilmiştir. Yapılan bir çalışmada kontrol grubu ile karşılaştırıldığında tip 2 DM’lilerde yüksek Aİ değerleri saptanmıştır (32). Ayrıca başka bir çalışmada artmış Aİ düzeyinin tip $2 \mathrm{DM}$ riskini arttırdığı belirtilmiştir (12). Belirtilen çalışmalardaki bulgulara benzer şekilde bu çalışmada da hem kadın hem de erkeklerde Aİ değeri yüksek olup, yüksek ateroskleroz riski taşıyanların sıklığı sırasıyla \%83.3 ve \%85.3 olarak saptanmıştır (Tablo 1). Ayrıca artmış Aİ değeri artmış HOMA-IR değerleriyle ilişkili bulunmuştur (Tablo 2). Obezite bozulmuş dislipidemiyle ilişkili olup (11) bu çalışmada bozulmuş dislipideminin değerlendirilmesinde kullanılan Aİ ile BKİ pozitif ilişkilidir (Tablo 3).
Bu çalışmada BKİnin hem Aİ hem de HOMA-IR'la pozitif ilişkili olması obezitenin hem insülin direnci hem de kardiyovasküler risk etmenini arttırdığını düşündürmektedir.

Obezite, kardiyovasküler risk etmenleri arasında yer alırken sadece genel obezite ile ilişkili olmayıp bölgesel vücut yağ dağılımıyla da yakından ilişkilidir (33). Ayrıca artan viseral yağ miktarının ve bel çevresinin, metabolik değişimin güçlü ve bağımsız belirleyicileri olduğu doğrulanmıştır (13). VAİ lipit parametrelerinde yer alan bir indeks olup viseral adipoz doku ve insülin direnci için önemli bir göstergedir (34). Bu çalışmada da VAİ insülin direnciyle pozitif ilişkili bulunmuştur. Bel çevresi, viseral yağlanma (Viscan \%) ve VAİ değeri HOMA-IR ile, bel çevresi ve VAİ ise Aİ indeksle pozitif ilişkili bulunmuştur. Yapılan bir çalışmada Aİ değeriyle bel çevresi ve BKİ pozitif ilişkili bulunmuştur (35). Bu çalışmaya benzer şekilde vücut yağ yüzdesinin Aİ ile ilişkisine bakılan başka bir çalışmada da viseral adipoziteyle Aİ pozitif ilişkili olarak saptanmıştır $(27,36)$. Abdominal obezitenin önemli göstergesi olan bel çevresi ( $r=0.241, p=0.016)$, hastalık riski göstergesi olan bel boy oranı $(r=0.244$, $\mathrm{p}=0.014)$ ve viseral yağlanma $(\%)(\mathrm{r}=0.709, \mathrm{p}=0.000) \mathrm{A} \dot{\mathrm{I}}$ ile pozitif ilişkili bulunmuştur. Bu çalışmayı destekler nitelikte aterojenik indeks vücut yağ yüzdesinin tip 2 DM’lilerde ilişkisine bakılan çalışmada benzer sonuçlar elde edilmiştir (36).

Yüksek TG ve düşük HDL-K düzeyleri, patolojik olmayan veya orta derecede LDL-K düzeyleri obezite ve insülin direnci ile ilişkilidir. Bu lipit profili aynı zamanda adipozite veya adipoz doku işlev bozukluğu ile bağlantılıdır. Obezite genellikle kardiyovasküler hastalıkların yanında dislipidemi ve insülin direnci patogenezinde yer alan ve en sık görülen komorbiditesi ise adipozite olan bir hastalıktır (37). $\mathrm{Bu}$ çalışmada abdominal adipozitenin göstergesi olarak VAİ $(r=0.323, p=0.001)$ ve kardiyovasküler risk belirteci olarak Aİ $(r=0.318, p=0.001)$ insülin direnci ile pozitif ilişkili bulunmuştur (Tablo 2 ve 3 ).

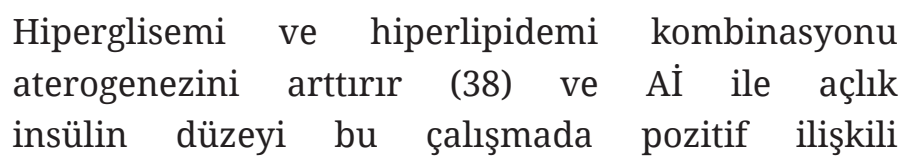


bulunmuştur. Aİ parametresinin insülin direnci ve artmış kardiyometabolik riski tanımlamak için kullanılabileceği yapılan başka bir çalışmada belirtilmiştir (34). Aİ ve VAİ değeri diyabetli bireylerde insülin direncini değerlendirmek için klinik yararlanılabilecek parametre olarak gösterilmektedir (34). Diyabetik hastalarda glisemik kontrolün iyileştirilmesi, obezite, abdominal obezite/adipozite ile lipit düzeylerinin kontrolü kardiyovasküler hastalık gelişme riskini azaltabilmektedir (39).

HbA1c'nin dislipidemiden bağımsız olarak bir birimlik artışı kardiyovasküler hastalık gelişme riskini yaklaşık \%18 arttırdığı bir çalışma ile belirtilirken bu çalışmada Aİ ile arasında anlamlı bir ilişki saptanmamıştır (40). Ayrıca yapılan bir çalışmada Aİ yaşla negatif ilişkili bulunmuş olup (35), bu çalışmada sadece erkeklerde negatif ilişkili saptanmıştır. Bunun aksine yaş ile Aİ’nın ilişkili olmadığı (41) ve/veya pozitif ilişkili olduğunu belirten (42) çalışmalarda bulunmaktadır.

Bu çalışmada tip 2 DM'li bireylerde obezitenin yaygın olduğu buna bağlı olarak abdominal obezitenin yüksek olduğu ve özellikle abdominal adipozitenin, insülin direnci ve kardiyovasküler hastalıkların değerlendirilmesinde önemli bir parametre olarak yer alan aterojenik indeksle pozitif ilişkili olduğu saptanmıştır. Artmış Aİ tip 2 DM riskinde artışla ilişkili olup kardiyovasküler hastalık gelişimini olumsuz etkilemektedir. Buna bağlı olarak Aİ tip 2 DM’li bireylerde kardiyovasküler hastalık risk tahmininde objektif bir gösterge olarak kullanılabilir. Ancak tip 2 DM’li bireylerde kardiyovasküler hastalıklar açısından en iyi risk tahminini bulmak için daha ileri çalışmalara gereksinme vardır.

Çıkar çatışması - Conflict of interest: Yazarlar çıkar çatışması olmadığını beyan ederler. - The authors declare that they have no conflict of interest.

\section{KAYNAKLAR}

1. Türkiye Endokrinoloji ve Metabolizma Derneği. Temel Diabetes Mellitus ve Komplikasyonlarının Tanı, Tedavi ve İzlem Kılavuzu. 9. Baskı Ankara, Miki Yayıncılık, 2017.
2. International Diabetes Federation. IDF Diabetes Atlas. 2017. Available at: http://www.diabetesatlas.org/ Erişim Tarihi: June 5, 2017.

3. Türk Diyabet Cemiyeti. TURDEP 2 sonuçlarının özeti. Available at: http://www.diabetcemiyeti.org/c/turdep-2sonuclarinin-ozeti Erişim Tarihi: June 5, 2017.

4. Türkiye Kronik Hastalıklar ve Risk Faktörleri Sıklığı Çalışması-2013, Sağlık Bakanlığı Yayın No:909, Ankara, 2013

5. Sesti G. Pathophysiology of insulin resistance. Best Pract Res Clin Endocrinol Metab 2006;20:665-679.

6. Karaçil MŞ, Akbulut G. Tip 2 diabetes mellitus ve beta glukan. Bes Diy Der 2013;41(3):242-246.

7. Kahn BB, Flier JS. Obesity and insulin resistance. J Clin Invest 2000;106:473-481.

8. Bhowmik B, Munir SB, Ahmed KR, Siddiquee T, Diep LM, Wright E, et al. Anthropometric indices of obesity and type 2 diabetes in Bangladeshi population: Chandra Rural Diabetes Study (CRDS). Obes Res Clin Pract 2014;8:201-298.

9. Marcadenti A, Fuchs FD, Moreira LB, Gus M, Fuchs SC. Adiposity phenotypes are associated with type-2 diabetes: LAP index, body adiposity index, and neck circumference. Atherosclerosis 2017;266:145-150.

10. Ginsberg HN. Insulin resistance and cardiovascular disease. J Clin Invest 2000;106:453-458.

11. Helvacı A, Tipi FF, Belen E. Obeziteye bağlı kardiyovasküler hastalıklar. Okmeydanı Tıp Dergisi 2014;30:5-14.

12. Zhu XW, Deng FY, Lei SF. Meta-analysis of Atherogenic Index of Plasma and other lipid parameters in relation to risk of type 2 diabetes mellitus. Prim Care Diabetes 2015;9:60-67.

13. Barbalho SM, Oshiiwa M, Sato Fontana LC, Ribeiro Finalli EF, Paiva Filho ME, Machado Spada AP. Metabolic syndrome and atherogenic indices in school children: A worrying panorama in Brazil. Diabetes Metab Syndr 2017;11:397-401.

14. Pekcan G. Hastanın beslenme durumunun saptanması. 2. Baskı Ankara, Sağlık Bakanlığı: 2012. ISBN : 978-975590-242

15. Amato MC, Giordano C, Galia M, Criscimanna A, Vitabile S, Midiri M, et al. Visceral Adiposity Index: a reliable indicator of visceral fat function associated with cardiometabolic risk. Diabetes Care 2010;33:920-922.

16. Motamed N, Perumal D, Zamani F, Ashrafi H, Haghjoo M, Saeedian FS, et al. Conicity index and waist-to-hip ratio are superior obesity indices in predicting 10year cardiovascular risk among men and women. Clin Cardiol 2015;38:527-534.

17. Freedman DS, Thornton JC, Pi-Sunyer FX, Heymsfield 
SB, Wang J, Pierson RN et al. The body adiposity index (hip circumference $\div$ height1.5 ) is not a more accurate measure of adiposity than is BMI, waist circumference, or hip circumference. Obesity 2012;20:2438-2444.

18. Holmes DT, Frohlich J, Buhr KA. The concept of precision extended to the atherogenic index of plasma. Clin Biochem 2008;41:631-635.

19. Matthews DR, Hosker JP, Rudenski AS, Naylor BA, Treacher DF, Turner RC. Homeostasis model assessment: insulin resistance and beta-cell function from fasting plasma glucose and insulin concentrations in man. Diabetologia 1985;28:412-419.

20. Özdogan E, Özdogan O, Altunoglu EG, Köksal AR. Tip 2 diyabet hastalarında kan lipid düzeylerinin HbA1c ve obezite ile iliskisi. Şişli Etfal Hastanesi Tıp Bülteni 2015;49:248-254.

21. Ginter E, Simko V. Type 2 diabetes mellitus, pandemic in 21st century. Adv Exp Med Biol 2012;771:42-50.

22. Güven GS, Gürlek A. Metabolik sendrom ve insülin direnci. Acta Medica 2004;35:96-99.

23. Temizhan A. Abdominal obesity and cardiometabolic risk/Abdominal obezite ve kardiyometabolik risk. Anadolu Kardiyol Derg 2007;7:35-37.

24. Taniguchi A, Nakai Y, Sakai M, Yoshii S, Hamanaka $\mathrm{D}$, Hatae $\mathrm{Y}$, et al. Relationship of regional adiposity to insulin resistance and serum triglyceride levels in nonobese Japanese type 2 diabetic patients. Metabolism 2002;51:544-548.

25. Banerji MA, Chaiken RL, Gordon D, Kral JG, Lebovitz HE. Does intra-abdominal adipose tissue in black men determine whether NIDDM is insulin-resistant or insulin-sensitive? Diabetes 1995;44:141-146.

26. Anan F, Masaki T, Umeno Y, Iwao T, Yonemochi H, Eshima N, et al. Correlations of visceral fat accumulation and atherosclerosis in Japanese patients with type 2 diabetes mellitus. Metabolism 2008;57:280-284.

27. Gastaldelli A, Miyazaki Y, Pettiti M, Matsuda M, Mahankali S, Santini E, et al. Metabolic effects of visceral fat accumulation in type 2 diabetes. J Clin Endocrinol Metab 2002;87:5098-5103.

28. Steiner G, Vranic M. Hyperinsulinemia and hypertriglyceridemia, a vicious cycle with atherogenic potential. Int J Obes 1982;6:117-124.

29. Li N, Fu J, Koonen DP, Kuivenhoven JA, Snieder H, Hofker MH. Are hypertriglyceridemia and low HDL causal factors in the development of insulin resistance? Atherosclerosis 2014;233:130-138.

30. Shen S, Lu Y, Dang Y, Qi H, Shen Z, Wu L, et al. Effect of aerobic exercise on the atherogenic index of plasma in middle-aged Chinese men with various body weights. Int J Cardiol 2017;230:1-5.

31. Dobiasova M, Frohlich J. The new atherogenic plasma index reflects the triglyceride and HDL-cholesterol ratio, the lipoprotein particle size and the cholesterol esterification rate: changes during lipanor therapy. Vnitr Lek 2000;46:152-156.

32. Hu YM, Tian HM, Liu R, Chen X. Atherogenic index of plasma is associated with carotid intima-media thickness in patients with type 2 diabetes mellitus. Sichuan Da Xue Xue Bao Yi Xue Ban 2004;35:696-698.

33. Ran XW, Li XS, Tong NW, Li QF, Tang BD, Li XJ. Body fat distribution: its characteristics and relationship to cardiovascular risk factors in obese Chinese. Sichuan Da Xue Xue Bao Yi Xue Ban 2004;35:699-703.

34. Uruska A, Zozulinska-Ziolkiewicz D, Niedzwiecki P, Pietrzak M, Wierusz-Wysocka B. TG/HDL-C ratio and visceral adiposity index may be useful in assessment of insulin resistance in adults with type 1 diabetes in clinical practice. J Clin Lipidol 2018 Jan 3 [Epub ahead of print] doi: 10.1016/j.jacl.2018.01.005.

35. Niroumand $S$, Khajedaluee $M$, Khadem-Rezaiyan $M$, Abrishami M, Juya M, Khodaee G, et al. Atherogenic Index of Plasma (AIP): A marker of cardiovascular disease. Med J Islam Repub Iran 2015;29 (240):1-9.

36. Song $\mathrm{P}, \mathrm{Xu} \mathrm{L}, \mathrm{Xu}$ J, Zhang HQ, Yu CX, Guan QB, et al. Atherogenic index of plasma is associated with body fat level in type 2 diabetes mellitus patients. Curr Vasc Pharmacol. 2018 Jan 3 [Epub ahead of print], doi: 10.217 4/1570161116666180103125456.

37. Guardiola M, Sola R, Vallve JC, Girona J, Godas G, Heras $\mathrm{M}$, et al. Body mass index correlates with atherogenic lipoprotein profile even in nonobese, normoglycemic, and normolipidemic healthy men. J Clin Lipidol 2015;9:824-831.

38. Levitt Katz LE, Bacha F, Gidding SS, Weinstock RS, El Ghormli L, Libman I, et al. Lipid profiles, inflammatory markers and insulin therapy in youth with type 2 diabetes. J Pediatr 2018;196:208-216.

39. Gotto AM, Moon JE. Management of cardiovascular risk: the importance of meeting lipid targets. Am J Cardio 2012;110:3-14.

40. Selvin E, Marinopoulos S, Berkenblit G, Rami T, Brancati FL, Powe NR, et al. Meta-analysis: glycosylated hemoglobin and cardiovascular disease in diabetes mellitus. Ann Intern Med 2004;141:421-431.

41. Nansseu JRN, Moor VJ, Nouaga ME, Zing-Awona B, Tchanana G, Ketcha A. Atherogenic index of plasma and risk of cardiovascular disease among Cameroonian postmenopausal women. Lipids Health Dis 2016;15(49):2-5.

42. Wang Y-M, Chen X-F, Yuan Q. Analysis on levels of nonhigh density lipoprotein cholesterol and atherogenic index of plasma in normal population. Zhejiang Prev Med 2008;20:10-14. 